\title{
TsZ WAH MA* \\ EVERYDAY LIFE EMOTIONS DURING ANTI-FUGITIVE OFFENDERS ORDINANCE PROTESTS IN HONG KONG
}

(Received: 21 October 2019; accepted: 5 April 2020)

This experience sampling study investigated the impact of political movement (i.e. Anti-Fugitive Offenders Ordinance Protests) on everyday emotional reactivity and dynamics. Participants who finished our experience sampling during Movement $(18-70$ years; $n=100)$ and matched sample $(18-70$ years; $\mathrm{n}=100)$ reported positive and negative emotions seven times a week for five weeks. Hierarchical linear modeling revealed that during the Movement, participants reported lower positive emotions and higher negative emotions, and lower positive emotional inertia and higher negative emotional inertia. This study is the first of its kind to investigate different aspects of everyday emotional experiences during political movements. Participants perceived significant changes in their everyday events although the Movement was not long and not severely violent. This study highlights the importance of investigating everyday emotions of people in other more serious conflict and post-conflict settings.

Keywords: Fugitive Offenders Ordinance; emotion; everyday life; political movement; Hong Kong

\section{Introduction}

There is a deficit of knowledge about whether people have different emotional experiences in everyday life during a social movement compared with people during a period without a major social movement. Moreover, one important limitation of the previous studies was that it used cross-sectional designs to examine the relationships between political movement and emotional well-being. Social movement is not static but incubates, develops, and changes over time (DUPONT \& PASSY 2011; KURZMAN 2015; LAGI et al. 2011). This study aims to (1) investigate everyday emotional experience during a political movement in Hong Kong, and (2) to examine the variability,

\footnotetext{
Tsz Wah Ma, Department of Surgery, The Chinese University of Hong Kong, Sha Tin, NT, Hong Kong, matszwah@gmail.com.
} 
instability, and inertia of emotional experience between a political movement group and a comparison group. A thorough investigation was conducted on emotional reactivity and variations in it, namely, variability, instability, and persistence. The AntiFugitive Offenders Ordinance Protests in Hong Kong would be introduced. Then conceptual and empirical literature on these emotional variables and the associations of them with psychological distress and well-being among clinical and healthy populations were reviewed.

\section{Fugitive Offenders Ordinance}

The Fugitive Offenders Ordinance has become the public attention since the case of a young Hong Kong woman who disappeared in Taiwan in February 2018. Taiwanese authorities suspected her boyfriend as having killed her and sought his return to Taiwan to face murder charges. But there are no general provisions for the transfer of criminal suspects between Hong Kong and Taiwan. Thus, the government has proposed amendments to the Fugitive Offenders Ordinance, which would apply to all legal jurisdictions that do not at present have a full-scale cooperation agreement with Hong Kong.

However, according to a public opinion poll conducted by the University of Hong Kong (2019), it shows that the largest proportion of citizens is opposed to this amendment. It is also interesting that both the supporters of the pan-democrats, the moderates, and those without any political allegiance, also demonstrated a clear opposition stand on the amendment. Although the government later proposed six extra measures for protection in order to address public concern, the controversy over the Fugitive Offenders Ordinance remains intense.

The Fugitive Offenders Ordinance has finally triggered large-scale protests on 9 June, 2019. Many large-scale protests have also been occurring subsequently in Hong Kong in June. An estimated over one million of the 7.2 million citizens have reportedly participated in the related protests (CHEN 2019). The Anti-Fugitive Offenders Ordinance Protests were the largest-scale social movement in Hong Kong since the Umbrella Movement in 2014 (CHAN 2014). There were originally violent clashes between protesters and the police outside the Central Government Offices and Hong Kong Police Headquarters, some of which involved pepper sprays. Also, other rounds of more severe and massive battles broke out across the different districts and shopping malls. These clashes resulted in a cumulation of at least 1000 injuries that required emergency room visits (HuI 2019).

\section{Emotion and Political Movement}

Positive emotions are conceptualized as states of feeling pleasant such as joy, pride, contentment, or excitement (FORD et al. 2018). Evidence exists that positive emotions are a crucial component of both mental and physical health (GRUBER et al. 2011). Meanwhile, negative emotions are defined as unpleasant or unhappy emotions, 
which are evoked in individuals to express a negative effect towards an event or person (ForD et al. 2018).

Emotion is one of the important elements of social movements (JORDANS et al. 2012). Emotion impacts mobilization, demobilization, and solidarity among protestors in social movements (BENSKI \& LANGMAN 2013; JASPER 2014). Understanding the sources of political threat results in feelings of hatred, suspicion, and indignation, which then powerfully mobilize the movements and protest actions (JASPER 2014). Protests could be viewed as a form of collective action and rely heavily on the participants' sense of belonging to the movements and whether the cause of action resonates with the participants' emotions (RASMUSSEN \& ANNAN 2009; RASMUSSEN et al. 2010). Meanwhile, immersion within the collective identity brings about positive experiences and positive emotions (ROBERTS et al. 2010). The proposed reason is that the collectivism in social movements originates from the shared meanings and reciprocal emotions toward fellow group members, such as enthusiasm and assertiveness concerning the goals of the movements (ROBERTS et al. 2010).

Existing evidence further suggests that positive and negative emotional experiences are likely highly variable and dependent upon the conditions of social movements. However, there is limited study on the psychological impact of political movements, not to mention the investigation of everyday life events and emotional experience in the midst of wars, conflicts, or political unrests (SABLONNIÈRE et al. 2013). For example, Brazilians expressed more protest-related negative than positive emotions during the summer of 2013, a period of conflicts and riots across more than 100 cities in Brazil (CosTA et al. 2015). Patterns of emotional changes could be highly related to psychological distress and well-being (RoEKEL et al., 2015; WiCHERS et al. 2009). Moreover, Egyptian citizens who were injured in political demonstrations reported higher levels of psychiatric symptoms than patients who experienced physical trauma from other causes (PAPANIKOLAOU et al., 2013). Hong Kong Chinese $(\mathrm{n}=1,206)$ reported significant levels of anxiety symptoms $(33 \%)$ and depressive symptoms (10\%) during the Anti-Fugitive Offenders Ordinance Protests (MA 2019).

However, one important limitation of the above-mentioned previous studies was that they used cross-sectional designs to examine the relationships between political movements and emotional well-being. Although these correlational designs studies provided a good insight into the association between the political movements and the citizens' mental health, they may have three major issues. First, retrospective selfreport measures of emotional experiences may well produce inaccurate results on assessing ongoing emotional experiences due to biases of memory storage and recall. No study to date has investigated everyday life emotional experiences of people in the midst of social and political movements. Second, they were conducted after the movement ended. The lag period might have influenced the emotional states of the general population. Third, none of the previous studies have provided clear definitions on emotional dynamics during political movements. 


\section{Everyday emotional reactivity}

Emotional reactivity refers to the average intensity or magnitude of people's emotional responses to different events. Cognitive theories suggest that people with depression are more likely to demonstrate a negative inferential style, rumination over negative events and emotions, and selective attention to negative information in response to stressors (DAVIDSON 2002). Higher negative emotional reactivity reflects a failure to regulate negative emotions in everyday life, contributing to heightened depressive symptoms (O'NeILL et al. 2004). Less intense responses to negative events and faster recovery from the responses have been underscored by a number of theoretical frameworks as being indicative of human resilience (KASHDAN \& ROTTENBERG 2010).

Higher negative emotional reactivity in everyday life reflects a failure to regulate negative emotions and, thus, poorer mental health (COHEN et al. 2005; PARRISH 2011). Higher negative emotions in negative events have also been found to predict higher affective symptoms and to increase the risk of major depressive disorder (MDD) among a community female twin sample (Wichers et al. 2009). Among women with histories of MDD, higher negative emotional reactivity predicted higher subsequent affective symptoms, controlling for the severity of previous MDD symptoms and trait neuroticism (WICHERS et al. 2010). Patients undergoing weekly cognitive therapy for emotional disorders demonstrated lower levels of anxiety and depressive symptomatology (GUNTHERT et al. 2006).

Positive emotional reactivity has received relatively less attention but some recent evidence suggests its adaptive utility. Among people vulnerable to or affected by major depressive disorder (MDD), higher positive emotional reactivity in everyday life predicted lower affective symptoms and a higher effectiveness of pharmaceutical treatment, especially among women with childhood trauma and recent stressful events (GESCHWIND et al. 2010; 2011).

\section{Everyday emotional variability and instability}

Emotional variability is defined as the extent to which the intensity of emotional reactions deviates from the average level over time, whereas emotional instability takes into account variability as well as temporal progressions of changes in emotional reactivity over time (JAHNG 2008). Variations in emotional reactivity can be assessed by taking into account the frequency of changes in emotions over time on top of average intensity (TRULL et al. 2008).

The variability and/or instability of everyday negative emotions predict poorer mental health. Negative emotional variability in everyday life was associated with higher anxiety and depressive symptoms among 83 women with a major depressive disorder (MDD) (WICHERs et al. 2010). People with social anxiety relative to healthy controls reported lower and unstable positive emotions but higher and stable negative emotions over two weeks of daily diaries (FARMER \& KASHDAN 2014). While children and adolescents with MDD reported decreased negative emotions 
over an eight-week cognitive-behavioral treatment, everyday instability of negative emotions - especially anger and sadness reported between Friday and Monday - was higher than that of healthy controls (SILK et al. 2011).

Similarly, the variability and instability of positive emotions could have detrimental impact on mental health. Depressive symptoms predicted a higher variability and instability of positive emotions in the everyday life of a sample of early and late adolescents (ROEKEL et al., 2015). Moreover, the variability of positive emotions predicted higher anxiety and depressive symptoms, as well as lower global functioning and life satisfaction, whereas the instability of positive emotions predicted higher depressive symptoms and lower subjective happiness among the samples of American and French adults (GRUBER et al. 2013).

Specifically, negative emotional instability in everyday life predicted higher depressive symptoms, independently of the effects of average negative emotional reactivity and variability (KovAL et al. 2013). For example, compared to non-depressed controls, people with a major depressive disorder demonstrated a higher than average positive and negative emotional reactivity and higher negative emotional instability over seven to eight days (PE et al. 2015; THOMPSON et al. 2012). However, people with depression and controls did not differ in positive emotional instability, or in positive and negative emotional variability (THOMPSON et al. 2012).

\section{Everyday emotional inertia}

Emotional inertia is defined as the extent to which emotional states tend to persist instead of changing over time (HouBEN et al. 2015; KuPPENS et al. 2010). The emotional context insensitivity hypothesis proposed that negative emotions that persist across the everyday situations contribute to poorer mental health and adjustment (ChIDA \& HAMER 2008). Compared to nondepressed people, individuals with depression reported similar levels of sadness following watching a sad movie, but the latter also reported higher levels of sadness following watching neutral and happy movies (ROTTENBERG et al. 2005; ROTTENBERG et al. 2002). The persistence of both positive and negative emotions in everyday life, in aggregate across 14 consecutive days, was inversely associated with self-esteem among college students (KuPPENS et al. 2010). Nevertheless, it should be noted that when considered individually, more persistent positive emotions in everyday life predicted lower subsequent depressive symptoms among a community sample of women, and better responses to treatments among individuals with depressive disorders (HÖHN et al. 2013).

\section{The present study}

Whereas most previous research has adopted a cross-sectional design, this study adopts the experience sampling method (ESM) to investigate the impact of political movement (i.e., the Anti-Fugitive Offenders Ordinance Protests) on everyday emotions. ESM is a research method focused on real-time data capture and is characterized 
by capturing events at the moment of occurrence (STONE et al. 2007). Retrospective self-report measures of emotional experiences from previous studies may well produce different results compared to the ESM of assessing ongoing emotional experiences, due to biases of memory storage and recall. Relatively much less evidence has been obtained using ESM. a sample of Hong Kong Chinese during the Anti-Fugitive Offenders Ordinance Protests was recruited and assessed. An age-matched and sexmatched comparison group was used before the Anti-Fugitive Offenders Ordinance Protests occurred, which is a period without major political conflicts and movements. This study hypothesizes the following:

Hypothesis 1: During the political movement, people experience lower positive emotions but higher negative emotions (i.e., emotional reactivity).

Hypothesis 2: During the political movement, people experience more variable and unstable positive and negative emotions, and less inert positive emotions but more inert negative emotions (i.e., emotional dynamics).

\section{Method}

\subsection{Participants and procedure}

An experience sampling survey was conducted between July and October, 2019 (the major protest started on 9 June 2019 and still continues) by stratified probability sampling from a database representative of the population (Census and Statistics Department 2011), upon obtaining the written consent from respondents. Inclusion criteria were (1) Chinese ethnicity, (2) Cantonese fluency (the most commonly spoken Chinese language and the mother tongue of $90 \%$ of the population in Hong Kong), and (3) an elementary education level or above. Individuals with a history of psychiatric conditions and a presence of cognitive impairments were excluded from the study.

Participants were instructed to report everyday positive and negative emotions over five weeks (i.e. 35 days). The assessment period covered twenty-five weekdays and ten weekend days. Items were presented in black ink on a white background. Each participant received extensive individual instructions and trainings on the ESM tasks. On each sampling day, participants were required to report their everyday positive and negative emotions from 6-12 PM in case they were available to fill in the questionnaires. If a participant responded to fewer than six sampling moments on a given week, the EMA period would be extended for one week. The compliance rate was $89.8 \%$.

\subsection{Measures}

\subsubsection{Sociodemographic characteristics}

A standardized proforma was used to obtain demographic information including age in years, sex, marital status, education level, employment status, monthly household income, and years of residence in Hong Kong. 


\subsubsection{Everyday life emotions}

At each sampling moment, positive emotions and negative emotions were first assessed using 12 items (HAMID \& CHENG 1996). Six items assessed positive emotions and negative emotions, respectively. The six items for positive emotions are: alertness, attentiveness, determination, enthusiasm, excitement, and pride; while the six items for negative emotions are: distress irritableness, jitteriness, nervousness, being scared and being upset. Participants used a five-point scale $(0=$ very slightly or not at all, $2=$ moderately, $4=$ very much) to indicate the extent to which they experience each emotional state at the moment. Separate summation scores were calculated for positive and negative emotions (range $=0-24$ ). In the current administration, alphas were 0.95 and 0.93 for positive and negative emotion subscales, respectively.

\subsubsection{Positive and negative emotional dynamics}

First, variability of positive and negative emotions was calculated using standard deviation at each occasion. Second, instability was indicated by square successive differences (SSD) between assessment points. We preprocessed the data by calculating the time series of squared successive differences, referred to as SSDij, in which " referred to person and ' $\mathrm{j}$ ' referred to session. The series of SSDij were calculated separately for positive and negative emotions, with variability in the timing of assessment taken into account (JAHNG et al. 2008). SSDij was log-transformed to adjust for skewness of the distribution, and the zero values of SSDij were replaced with half of the smallest nonzero value to allow for $\log$ transformation. Third, positive and negative emotional inertia was indicated by autocorrelations between assessment points.

\subsection{Analytic plan}

Mann Whitney $U$ tests were used to identify any differences in sociodemographic characteristics between the Anti-Fugitive Offenders Ordinance Protests group and the matched group. No significant group differences were identified in all demographic characteristics. Hierarchical linear modeling (HLM) was conducted using HLM 7.0 (RAUDENBUSH 2011).

HLM used all available data, the data consisting of a maximum of 35 sets for each participant. All models consisted of two levels, sessions (Level 1) and individuals (Level 2). To address the study hypotheses, eight models were constructed to test the associations of social movement and emotional well-being. The dependent variables comprised the following eight Level 1 variables, which included (1) positive and negative emotions, (2) positive and negative emotional variability, instability, and inertia. Level 2 consisted of group membership $(0=$ Matched Group, $1=$ Group during Anti-Fugitive Offenders Ordinance Protests) as the predictor. Separate models were constructed to test group differences in emotional reactivity and dynamics (i.e., variability, instability, and inertia). 


\section{Results}

\subsection{Emotional reactivity and dynamics during the protests}

Among the 200 participants, 100 finished the ESM during the Anti-Fugitive Offenders Ordinance Protests (mean days since the start of the Anti-Fugitive Offenders Ordinance Protests $=46.15, \mathrm{SD}=6.26$, range $=27-65$ ). The detailed sample characteristics are summarized in Table 1. Hierarchical linear modeling revealed that during the Anti-Fugitive Offenders Ordinance Protests, participants reported lower positive emotions (Estimate $=-3.03, S E=0.96, t=-3.16, \mathrm{CI}=-4.91,-1.15, p<0.001$ ), and higher negative emotions (Estimate $=2.43, S E=0.77, t=3.16, \mathrm{CI}=0.92,3.93, p<$ 0.001 ), relative to the matched sample during a period without major social/political movements. Significant group differences were also identified in positive and negative

Table 1

Demographics of the participants

\begin{tabular}{lcc}
\hline & Social Movement Group & Comparison group \\
\hline Mean age (SD) & $44.39(17.76)$ & $44.01(17.63)$ \\
Range & $18-70$ & $18-70$ \\
Sex (female) & 50 & 50 \\
Marital status & 54 & 52 \\
Married & 46 & 48 \\
Single/divorced/widowed & & \\
Education level & 0 & 0 \\
Primary education or below & 60 & 58 \\
Secondary education & 40 & 42 \\
Tertiary education or above & & \\
Employment status & 90 & 88 \\
Employed & 2 & 3 \\
Unemployed & 8 & 9 \\
Retired & & 28 \\
Monthly household income & 10 & 19 \\
$\leq$ HKD10000 & 12 & 31 \\
HKD10001-20000 & 18 & \\
HKD20001-30000 & 33 & \\
HKD30001-40000 & 27 & \\
$\geq$ HKD40001 & & \\
\hline
\end{tabular}

${ }^{*} \mathrm{EUR} \$ 1 \approx \mathrm{HK} \$ 8.5$ 
emotional inertia, in general (Estimate $=-3.04,2.44, S E=0.96,0.77, t=-3.18,3.17$, $\mathrm{CI}=-4.93,-1.17$ and $0.93,3.95, p<0.001)$. Lower positive emotional inertia and higher negative emotional inertia were observed among the group during the AntiFugitive Offenders Ordinance Protests, controlling for demographic covariates. No group difference was identified in positive and negative emotional variability and instability (Estimate $=-0.91$ to $1.54, S E=0.15$ to $1.88, t=-1.70$ to $1.35, p=0.10$ to $0.85)$. The results are summarized in Table 2.

Table 2

Hierarchical linear modeling of group differences in emotional reactivity and dynamics.

\begin{tabular}{|c|c|c|}
\hline & \multicolumn{2}{|c|}{ Group difference } \\
\hline & Estimate (SE) & $p$ \\
\hline Average $P A$ & $-3.03(0.96)$ & $<0.01$ \\
\hline Average NA & $2.43(0.77)$ & $<0.01$ \\
\hline$P A$ variability & $-0.06(0.25)$ & 0.80 \\
\hline NA variability & $0.21(0.32)$ & 0.52 \\
\hline PA instability & $-0.08(0.15)$ & 0.59 \\
\hline NA instability & $0.15(0.17)$ & 0.38 \\
\hline PA inertia & $-3.05(0.83)$ & $<0.01$ \\
\hline NA inertia & $2.44(0.77)$ & $<0.01$ \\
\hline \multicolumn{3}{|c|}{ Random Effects } \\
\hline \multicolumn{3}{|l|}{ Level 1 Variance } \\
\hline Average $P A$ & $9.94(3.15)$ & \\
\hline Average NA & $9.54(2.94)$ & \\
\hline PA variability & $3.53(1.88)$ & \\
\hline$N A$ variability & $2.92(1.71)$ & \\
\hline PA instability & $1.75(1.32)$ & \\
\hline NA instability & $1.27(1.13)$ & \\
\hline PA inertia & $8.70(2.95)$ & \\
\hline NA inertia & $6.79(2.61)$ & \\
\hline \multicolumn{3}{|l|}{ Level 2 Variance } \\
\hline Average $P A$ & $21.93(4.68)$ & $<0.01$ \\
\hline Average NA & $13.97(7.94)$ & $<0.01$ \\
\hline PA variability & $1.37(1.17)$ & $<0.01$ \\
\hline NA variability & $2.36(1.54)$ & $<0.01$ \\
\hline PA instability & $0.47(0.68)$ & $<0.01$ \\
\hline NA instability & $0.61(0.78)$ & $<0.01$ \\
\hline PA inertia & $22.37(4.73)$ & $<0.01$ \\
\hline NA inertia & $13.80(3.71)$ & $<0.01$ \\
\hline
\end{tabular}




\section{Discussion}

The current findings are partially consistent with the previous literature on emotion. Hierarchical linear modeling found that people during the protests did not experience more positive and negative emotional variability and instability, but they did report lower positive emotions and higher negative emotions, in general. Lower positive emotional inertia and higher negative emotional inertia were also reported during the protests. The findings on negative emotional dynamics were consistent with previous evidence (Gruber et al. 2013; Houben et al. 2015; Pe et al. 2015).

This study is the first of its kind to collect ESM data on emotions in the everyday life of people during a political movement. Previous studies have found a questionable correspondence between cognitions and emotions reported in ESM and retrospective self-report, possibly due to biases of memory storage and recall (Moskowitz et al. 2009). Contributing to previous literature, we found that people reported lower positive emotions and higher negative emotions, and less positivity of favorable events, notwithstanding that they experienced a similar number of positive and negative events during the Anti-Fugitive Offenders Ordinance Protests. Analyses of emotional dynamics revealed that their lower positive emotions were more variable, whereas their higher negative emotions were more stable during the Movement. Even though the Anti-Fugitive Offenders Ordinance Protests was not long and not severely violent, participants perceived significant changes in their everyday emotions. Our findings highlight the importance of investigating people's everyday emotions in other, more serious conflict and post-conflict settings. For example, civil war has been waged in Syria since 2011. Over 220,000 Syrians have been killed and 800,000 have been injured; $75 \%$ of the people are still living in poverty (United Nations 2015). In countries undergoing prolonged pro-democracy movements and armed conflicts, as in Syria, people are likely to experience negative rather than positive events every day, with occasional positive emotions at lower levels and stably higher negative emotions compared with people in countries without major conflicts.

Our findings indicated that a significant association exists between political movements and both positive and negative emotional reactivity. Theoretical and empirical literature has suggested that emotional context insensitivity is maladaptive, and associated with increased psychiatric symptoms (RotTENBERG et al. 2005). Previous studies have demonstrated reduced flexibility in positive and negative emotional reactivity among individuals having major depressive disorder (Koval et al. 2015; ROTTENBERG et al. 2002; 2005). Regulatory flexibility is evaluated in accordance with three sequential processes to capture the person-situation dynamics in adaptation to stress: sensitivity to context, availability of a diverse repertoire of regulatory strategies, and responsiveness to feedback (BONANNO \& BURTON 2013). Sensitivity to context refers to the degree to which individuals could accurately perceive and understand situational demands and opportunities. Based on BONANNO and BURTON's (2013) regulatory flexibility perspective, participants undergoing the Anti-Fugitive Offenders Ordinance Protests could be less sensitive to positive cues, and find it 
more difficult to produce or upregulate context-congruent positive emotions. Despite perceiving similar positive and negative events during political movements, individuals might be more likely to perceive lower positivity, and experience lower and variable positive emotions and stably higher negative emotions, during positive events. The results were similar to those that were obtained in the everyday life of individuals with social anxiety disorder (FARMER \& KASHDAN 2014).

In the heat of pessimism toward Hong Kong's future and dissatisfaction with the government, savoring daily positive events and emotions during a social movement could be an important first step for safeguarding future subjective well-being, especially when positive events are possibly devalued and positive emotions are lower. The perceived capability of savoring positive events predicted higher daily positive emotional reactivity to positive events among college students in the United States (CARL et al. 2014). New Zealand college students reporting a higher savoring of positive events in their everyday life also demonstrated higher positive emotional reactivity to those events (JOSE et al. 2012). An important point to note is that these findings were obtained mainly from Caucasian college students and thus might not be readily generalizable to the current Chinese sample, although the perceived capability of savoring has been found to be adaptive among Chinese people (LIVINGSTONE \& SRIVASTAVA 2012; WERNER-SEIDLER et al. 2013). Therefore, it is important, both theoretically and empirically, to study how savoring during social movements contributes to physical and mental health across diverse populations.

\section{Limitations and conclusion}

Several limitations warrant cautions. First, this study was conducted in a relatively small sample of Hong Kong Chinese $(n=100)$ during the Anti-Fugitive Offenders Ordinance Protests. Sociocultural characteristics could limit the generalizability of the findings to people facing political movement in other socio-cultural contexts. Second, potential confounders such as preexisting mental and physical health issues and concurrent predictors - like exposure to the Anti-Fugitive Offenders Ordinance Protests - were not assessed. Unmeasured confounders could dilute the associations between predictors and outcomes, whereas concurrent predictors like exposure to the Movement could systematically impact emotional experiences. Third, the Anti-Fugitive Offenders Ordinance Protests group was defined as those who completed the study within the Movement (July-October, 2019). The protests still continue in Hong Kong and seem to become more violent and severe. Therefore, we cannot rule out the possibility that there will be more significant difference between the protest group and the control group in case the ESM is done in the later period.

Notwithstanding these limitations, the present study is one of the first to investigate everyday emotional reactivity and dynamics during political movement, and the extent to which these emotional variables predict psychiatric symptoms and subjective well-being post-movement. Social/political movements undoubtedly impact people's everyday emotions. This study provides an important evidence base for 
investigating emotions as one of the major domains in everyday life of people during the Anti-Fugitive Offenders Ordinance Protests. In recent years, protests and prodemocracy movements have been on-going, although in many parts of the world, they have yet to be politically successful. An increased number of people undergo a long-term adaptation following political movements, such as occasional armed conflicts, interpersonal violence, and leaving home countries as refugees. There is a body of literature recognizing daily stressors as a missing, yet essential, component for investigating the links of political conflicts and social unrest with mental health in the long-run. In addition to everyday emotions, systematic investigations are needed to explicate which, when, and how other everyday life processes contribute to both positive and negative health outcomes, over and beyond the immediate and usually traumatic exposure to political movement.

\section{References}

Benski, T., \& Langman, L. (2013) 'The Effects of Affects: The Place of Emotions in the Mobilizations of 2011', Current Sociology, 61, 525-40 (https://doi.org/10.1177/0011392113 479751).

Bonanno, G. A., \& Burton, C. L. (2013) 'Regulatory Flexibility an Individual Differences Perspective on Coping and Emotion Regulation', Perspectives on Psychological Science, 8, 591-612 (https://doi.org/10.1177/1745691613504116).

Carl, J.R., C.P. Fairholme, M.W. Gallagher, J. Thompson-Hollands \& D.H. Barlow (2014) 'The Effects of Anxiety and Depressive Symptoms on Daily Positive Emotion Regulation', Journal of Psychopathology and Behavioral Assessment 36, 224-36. (https://doi.org/ 10.1007/s10862-013-9387-9).

Census and Statistics Department (2011) Population Census-Summary Results, retrieved 8 Apr 2020 from http://www.census2011.gov.hk/pdf/summary-results.pdf.

Chan, J. (2014) 'Hong Kong's Umbrella Movement', The Round Table 103, 571-80 (https://doi.org/10.1080/00358533.2014.985465).

CHEN, Y.H. (2019) 'The Controversy of the Amendment of Anti-Extradition in Hong Kong-Threat to the People of Hong Kong', HOLISTICA - Journal of Business and Public Administration 10, 133-42 (https://doi.org/10.2478/hjbpa-2019-0033).

CHIDA, Y., \& M. HAMER (2008) 'Chronic Psychosocial Factors and Acute Physiological Responses to Laboratory-Induced Stress in Healthy Populations: a Quantitative Review of 30 Years of Investigations', Psychological Bulletin 134, 829-85 (https://doi.org/10.1037/a0016852).

Cohen, L.H., K.C. GunTherT, A.C., Butler S.C., O’Neill \& L.H. Tolpin (2005) 'Daily Affective Reactivity as a Prospective Predictor of Depressive Symptoms', Journal of Personality 73, 1687-1714 (https://doi.org/10.1111/j.0022-3506.2005.00363.x).

Costa, J.M., R. RotaBi, E.L. Murnane \& T: Choudhury (2015) 'It is not Only about GrievancesEmotional Dynamics in Social Media during the Brazilian Protests' in M. CHA, C. Mascolo $\&$ C. SAndvig, Eds., Proceedings of the Ninth International AAAI Conference on Web and Social Media (Palo Alto: AAAI Press) 594-97.

Davidson, R.J., D. Pizzagalli, J.B. Nitschke \& K. Putnam (2002) 'Depression: Perspectives from Affective Neuroscience', Annual Review of Psychology 53, 545-74 (https://doi.org/ 10.1146/annurev.psych.53.100901.135148). 
De la Sablonnière, R., E. Auger, D.M. Taylor, J, Crush \& D. McDonald (2013) 'Social Change in South Africa: a Historical Approach to Relative Deprivation', The British Journal of Social Psychology 52, 703-25 (https://doi.org/abs/10.1146/annurev.psych.53.100901. 135148).

Dupont, C. \& F. PAssy (2011) 'The Arab Spring or How to Explain those Revolutionary Episodes?' Swiss Political Science Review 17, 447-51 (http://dx.doi.org/10.1111/j.16626370.2011.02037.x).

FARMER, A.S. \& T.B. KASHDAN (2014) 'Affective and Self-Esteem Instability in the Daily Lives of People with Generalized Social Anxiety Disorder', Clinical Psychological Science 2, 187-201 (https://doi.org/10.1177/2167702613495200).

Ford, B.Q., P. LAM, O.P. JoHn \& I.B. Mauss (2018) 'The Psychological Health Benefits of Accepting Negative Emotions and Thoughts: Laboratory, Diary, and Longitudinal Evidence', Journal of Personality and Social Psychology 115, 1075 (https://doi.org/ 10.1037/pspp0000157).

Geschwind, N., F. Peeters, N. Jacobs, P. Delespaul, C. Derom, E. Thiery, J. van Os \& Wichers, M. (2010) 'Meeting Risk with Resilience: High Daily Life Reward Experience Preserves Mental Health', Acta Psychiatrica Scandinavica 122, 129-38 (https://dx.doi.org/ 10.1111/j.1600-0447.2009.01525.x).

Geschwind, N., N.A. Nicolson, F. Peeters, J. van Os, D. Barge-Schaapveld \& M. Wichers (2011) 'Early Improvement in Positive Rather than Negative Emotion Predicts Remission from Depression after Pharmacotherapy', European Neuropsychopharmacology 21, 241-47 (https://doi.org/10.1016/j.euroneuro.2010.11.004).

Gruber, J., P. Eidelman, S.L. Johnson, B. Smith \& A.G. Harvey (2011) 'Hooked on a Feeling: Rumination about Positive and Negative Emotion in inter-Episode Bipolar Disorder', Journal of Abnormal Psychology 120, 956-61 (https://doi.org/10.1037/a0023667).

Gruber, J., A. Kogan, J. Quoidbach \& I.B. Mauss (2013) 'Happiness is Best Kept Stable: Positive Emotion Variability is Associated with Poorer Psychological Health', Emotion 13, 1-6 (https://doi.org/10.1037/a0030262).

Gunthert, K.C., L.H. CoHEN, A.C. ButLer \& J.S. BeCK (2006) 'Predictive Role of Daily Coping and Affective Reactivity in Cognitive Therapy Outcome: Application of a Daily Process Design to Psychotherapy Research', Behavior Therapy 36, 77-88 (https://doi.org/10.1016/ S0005-7894(05)80056-5).

HAMid, P.N. \& S.T. Cheng (1996) 'The Development and Validation of an Index of Emotional Disposition and Mood State: The Chinese Affect Scale', Educational and Psychological Measurement 56, 995-1014 (https://doi.org/10.1177/0013164496056006006).

Höhn, P., C. Menne-Lothmann, F. Peeters, N.A. Nicolson, N. Jacobs, C. Derom, C., E. Thiery, J. vaN Os \& Wichers, M. (2013) 'Moment-to-Moment Transfer of Positive Emotions in Daily Life Predicts Future Course of Depression in Both General Population and Patient Samples', PLoS One 8, e75655 (https://doi.org/10.1371/journal.pone.0075655).

Hong Kong Extradition Law: Controversial Fugitive Bill Explained', Young Post, June 12, 2019; retrieved 8 Apr 2020 from https://yp.scmp.com/news/hong-kong/article/113289/hong-kongextradition-law-controversial-fugitive-bill-explained.

HuI, F. (2019) 'No Withdrawal, No Victory: Why Hongkongers Have not yet Won the War Against the Extradition Bill', HKFP (Hong Kong Free Press) 22 June 2019; retrieved 8 Apr 2020 from https://www.hongkongfp.com/2019/06/22/no-withdrawal-no-victory-hongkongers-notyet-won-war-extradition-bill/.

Houben, M., W.VAn Den Noortgate \& P. Kuppens (2015) 'The Relation between Short-Term Emotion Dynamics and Psychological Well-Being: a Meta-Analysis', Psychological Bulletin 141, 901-30 (https://doi.org/10.1037/a0038822). 
JAHNG, S., P.K. WoOD \& T.J. TRULL (2008) 'Analysis of Affective Instability in Ecological Momentary Assessment: Indices Using Successive Difference and Group Comparison Via Multilevel Modeling', Psychological Methods 13, 354-75 (https://doi.org/10.1037/a0014173).

JASPER, J.M. (2014) 'Constructing Indignation: Anger Dynamics in Protest Movements', Emotion Review 6, 208-13 (https://doi.org/10.1177/1754073914522863).

Jordans, M.J., M. SEmRau, G. Thornicroft \& M. van OMmeren (2012) 'Role of Current Perceived Needs in Explaining the Association between Past Trauma Exposure and Distress in Humanitarian Settings in Jordan and Nepal', The British Journal of Psychiatry 201, 276-81 (https://doi.org/10.1192/bjp.bp.111.102137).

Jose, P.E., B.T. Lim \& F.B. BRYANT (2012) 'Does Savoring Increase Happiness? a Daily Diary Study', Journal of Positive Psychology 7, 176-87 (https://doi.org/10.1080/17439760.2012. 671345).

Kashdan, T.B. \& J. Rottenberg (2010) 'Psychological Flexibility as a Fundamental Aspect of Health', Clinical Psychology Review 30, 865-78 (https://doi.org/10.1016/j.cpr.2010.03.001).

Koval, P., M.L. Pe, K. Meers \& P. Kuppens (2013) 'Affect Dynamics in Relation to Depressive Symptoms: Variable, Unstable or Inert? Emotion 13, 1132-41 (https://doi.org/10.1037/ a0033579).

Koval, P., A. Brose, M.L. Pe, M. Houben, Y. Erbas, D. Champagne, D. \& P. Kuppens (2015) 'Emotional Inertia and External Events: The Roles of Exposure, Reactivity, and Recovery', Emotion 15, 625-36 (https://doi.org/10.1037/emo0000059).

Kuppens, P., N.B. Allen \& L.B. SheEber (2010) 'Emotional Inertia and Psychological Maladjustment', Psychological Science 21, 984-91 (https://doi.org/10.1177/0956797610372634).

Kurzman, C. (2015) Terrorism Cases Involving Muslim-Americans, 2014 (Chapel Hill, NC: U of North Carolina).

Lagi, M., K.Z. Bertrand \& Y Ber-Yam (2011) The Food Crises and Political Instability in North Africa and the Middle East (Cambridge, UK: New England Complex Systems Institute).

Livingstone, K.M. \& S. SRIVASTAVA (2012) 'Up-Regulating Positive Emotions in Everyday Life: Strategies, Individual Differences, and Associations with Positive Emotion and Well-Being', Journal of Research in Personality 46, 504-16 (https://doi.org/10.1016/j.jrp.2012.05.009).

MA, T.W. (2019) 'The Impact of Anti-Fugitive Offenders Ordinance Protests on the Mental Health in the Hong Kong General Public', The International Journal of Indian Psychology 7, 35-45 (https://doi.org/10.25215/0703.066).

Moskowitz, D.S., J.J. Russell, G. SAdikaj \& R. Sutton (2009) 'Measuring People Intensively', Canadian Psychology 50, 131-40 (https://doi.org/10.1037/a0016625).

OCHA (2015) 2015 Syria Response Plan and 2015-2016 Regional Refugee and Resilience Plan, retrieved 8 Apr 2020 from https://docs.unocha.org/sites/dms/Syria/Overview\%20of\% 202015\%20Response\%20Plans\%20for\%20Syria\%20Crisis 150322.pdf.

O’Neill, S.C., L.H. CoHEN, L.H. Tolpin \& K.C. GunTHERT (2004) 'Affective Reactivity to Daily Interpersonal Stressors as a Prospective Predictor of Depressive Symptoms', Journal of Social and Clinical Psychology 23, 172-94 (https://doi.org/10.1521/jscp.23.2.172.31015).

Papanikolaou, V., M. Gadallah, G.R. Leon, E. Massou, G. Prodromitis, A. Skembris \& J. LeVeTt (2013) 'Relationship of Locus of Control, Psychological Distress, and Trauma Exposure in Groups Impacted by Intense Political Conflict in Egypt', Prehospital and Disaster Medicine 28, 423-27 (https://doi.org/10.1017/S1049023X13008601).

PARRish, B.P., L.H. COHEN \& J.P. LAURENCEAU (2011) Prospective Relationship between Negative Affective Reactivity to Daily Stress and Depressive Symptoms', Journal of Social and Clinical Psychology 30, 270-96 (https://doi.org/10.1521/jscp.2011.30.3.270). 
Pe, M.L., K. Kircanski, R.J. Thompson, L.F. Bringmann, F. Tuerlinckx, M. Mestdagh, J. Mata, S.M. Jaeggi, M. BuschKuehl, J. Jonides, P. Kuppens \& I.H. Gotlib (2015) 'Emotion-Network Density in Major Depressive Disorder', Clinical Psychological Science 3, 292-300 (https://doi.org/10.1177/2167702614540645).

Rasmussen, A. \& J. AnNan (2009) 'Predicting Stress Related to Basic Needs and Safety in Darfur Refugee Camps: a Structural and Social Ecological Analysis', Journal of Refugee Studies 23, 23-40 (https://doi.org/10.1093/jrs/fep044).

Rasmussen, A., L. Nguyen, J. Wilkinson, S. Vundla, S. Raghavan, K.E. Miller \& A.S. Keller (2010) 'Rates and Impact of Trauma and Current Stressors among Darfuri Refugees in Eastern Chad', American Journal of Orthopsychiatry 80, 227-36 (https://doi.org/10.1111/j.19390025.2010.01026.x).

Raudenbush, S.W., A.S. Bryk, Y. Cheong, R. Congdon \& M. du Toit (2011) HLM 7.0: Hierarchical Linear Modeling (Student) (Lincolnwood: Scientific Software International).

Roberts, B., E.Y. Damundu, O. Lomoro \& E. Sondorp (2010) 'The Influence of Demographic Characteristics, Living Conditions, and Trauma Exposure on the Overall Health of a Conflict-Affected Population in Southern Sudan', BMC Public Health 10, 518 (https://doi.org/ 10.1186/1471-2458-10-518).

RottenberG, J., K.L. Kasch, J.J. Gross \& I.H. GotLiB (2002) 'Sadness and Amusement Reactivity Differentially Predict Concurrent and Prospective Functioning in Major Depressive Disorder', Emotion 2, 135-46 (https://doi.org/10.1037/1528-3542.2.2.135).

RottenberG, J., J.J. Gross \& I.H. GotLiB (2005) Emotion Context Insensitivity in Major Depressive Disorder', Journal of Abnormal Psychology 114, 627-39 (https://doi.org/10.1037/0021843X.114.4.627).

Silk, J.S., E.E: Forbes, D.J. Whalen, J.L. JakubCak, W.K. Thompson, N.D. RYan, N. D., D.A. Axelson, B. Birmaher \& R.E. DAHL (2011) 'Daily Emotional Dynamics in Depressed Youth: a Cell Phone Ecological Momentary Assessment Study', Journal of Experimental Child Psychology 110, 241-57 (http://dx.doi.org/10.1016/j.jecp.2010.10.007).

Stone, A.A., S. Shiffman, A. AtienZa \& L. Nebeling (2007) The Science of Real-Time Data Capture: Self-Reports in Health Research (New York: Oxford UP).

Thompson, R.J., J. Mata, S.M. JaegGi, M. Buschkuehl, J. Jonides \& I.H. Gotlib (2012) 'The Everyday Emotional Experience of Adults with Major Depressive Disorder: Examining Emotional Instability, Inertia, and Reactivity', Journal of Abnormal Psychology 121, 81929 (https://doi.org/10.1037/a0027978).

Trull, T.J., M.B. Solhan, S.L. Tragesser, S. Jahng, P.K. Wood, T.M. Piasecki \& D. Watson (2008) 'Affective Instability: Measuring a Core Feature of Borderline Personality Disorder with Ecological Momentary Assessment. Journal of Abnormal Psychology 117, 647-61 (https://doi.org/10.1037/a0012532).

Hong Kong Extradition Law: Controversial Fugitive Bill Explained', Young Post, June 12, 2019; retrieved 8 Apr 2020 from https://yp.scmp.com/news/hong-kong/article/113289/hong-kongextradition-law-controversial-fugitive-bill-explained.

University of Hong Kong (2019) Survey on the "Fugitive Offenders Ordinance" Amendment, retrieved 29 Apr 2020 from https://www.hkupop.hku.hk/english/report/singming_extradition_bill/\#6.

van Roekel, E., T. Ha, M. Verhagen, E. Kuntsche, R.H.J. Scholte \& R.C.M.E. Engels (2015) 'Social Stress in Early Adolescents' Daily Lives: Associations with Affect and Loneliness', Journal of Adolescence 45, 274-83 (https://doi.org/10.1016/j.adolescence. 2015.10.012). 
Werner-Seidler, A., R. Banks, B.D. Dunn \& M.L. Moulds (2013) 'An Investigation of the Relationship between Positive Affect Regulation and Depression', Behaviour Research and Therapy 51, 46-56 (https://doi.org/10.1016/j.brat.2012.11.001).

Wichers, M., N. Geschwind, N. Jacobs, G. Kenis, F. Peeters, C. Derom, C., E. Thiery, Ph. Delespaul \& VAN Os, J. (2009) 'Transition from Stress Sensitivity to a Depressive State: Longitudinal Twin Study', The British Journal of Psychiatry 195, 498-503 (https://doi.org/ 10.1192/bjp.bp.108.056853).

Wichers, M., F. Peeters, N. Geschwind, N. Jacobs, C.J.P. Simons, C. Derom, E. Thiery, Ph. Delespaul \& Van Os, J. (2010) 'Unveiling Patterns of Affective Responses in Daily Life May Improve Outcome Prediction in Depression: a Momentary Assessment Study', Journal of Affective Disorders 124, 191-95 (https://doi.org/10.1016/j.jad.2009.11.010). 